REVISTA X, Curitiba, volume 13, n.1, p. 230-254, 2018.

Dossiê Especial: Português como Língua Adicional em contextos de minorias:

(co)construindo sentidos a partir das margens

BIZON \& DINIZ (Orgs.)

\title{
"DEPOIS DE TANTOS ANOS JUNTAS, VOCÊ SEQUER ME ENSINA SUA LÍNGUA": NARRATIVAS SOBRE QUESTÕES BASILARES DA POLÍTICA LINGUÍSTICA DA COMUNIDADE SURDA BRASILEIRA ${ }^{1}$
}

"After all these years together, you don't even teach me your language": perceptions of basic issues of the Brazilian deaf community linguistic policy.

Danielle COELHO LINS, IEL-UNICAMP e INES ${ }^{2}$

RESUMO: O presente artigo objetiva discutir como jovens estudantes surdos compreendem questões basilares da luta da comunidade surda brasileira - fortalecida ao longo das últimas décadas - em favor de uma Educação Bilíngue para Surdos que institui, dentre outras premissas, o ensino da LIBRAS como primeira língua e português como segunda língua. Dessas questões basilares relativas ao português, destacam-se: os usos sociais da língua nas vidas desses estudantes e as relações que eles constroem com pessoas ouvintes. Para tanto, são analisadas narrativas produzidas em conversas com alunos do sexto e sétimo anos do Ensino Fundamental II de uma escola de surdos localizada na cidade do Rio de Janeiro. Essas conversas indicam avanços em direção à educação bilíngue pretendida, como, por exemplo, a percepção de que o uso do português, oral e/ou escrito, não é, necessariamente, uma prática geradora de traumas, como frequentemente relatado por gerações anteriores à Lei de LIBRAS (BRASIL, 2002). Contudo, outras narrativas ainda indiciam pontos de conflito, tais como os relatos de que algumas famílias de surdos não sabem ou sabem pouca língua de sinais. Espera-se, com a discussão promovida a partir das vozes dos estudantes aqui focalizados, levantar e observar os pontos mencionados para que possam subsidiar, em trabalhos futuros, a busca de caminhos para a operacionalização de uma educação bilíngue para surdos.

PALAVRAS-CHAVE: Português escrito para surdos; Estratégias de aprendizagem; Políticas linguísticas.

ABSTRACT: The present paper aims at discussing how young deaf students understand basic issues in the struggle of the Brazilian deaf community - strengthened during the last decades - in favor of the Bilingual Education to the Deaf that comprehends, among other things, the teaching of LIBRAS as the first language and Portuguese as the second one. Among these basic issues related to Portuguese, some are

\footnotetext{
${ }^{1}$ Ainda que se pretenda plural, a comunidade surda costuma intitular-se no singular nos documentos que produz, acredito, como forma de fortalecimento em sua luta política e linguística.

${ }^{2}$ Doutoranda em Linguística Aplicada no Departamento de Linguística Aplicada do Instituto de Estudos da Linguagem (IEL), Unicamp. Professora de Língua Portuguesa e Literatura do Instituto Nacional de Educação de Surdos (INES). Email: danielle.lins@ymail.com
} 
REVISTA X, Curitiba, volume 13, n.1, p. 230-254, 2018.

Dossiê Especial: Português como Língua Adicional em contextos de minorias:

(co)construindo sentidos a partir das margens

BIZON \& DINIZ (Orgs.)

emphasized: the social uses of the language in the students' lives and the relationship they build with hearing people. For so, we analyze narratives produced during conversations with students from the sixth and the seventh grades of the Ensino Fundamental II of a deaf students' school, located at the city of Rio de Janeiro. The conversations show some progress in relation to the bilingual education that is aimed, as, for instance, the perception that the usage of Portuguese, oral and/or written, is not, necessarily, such a traumatic experience as the one frequently related by generations that came before the LIBRAS Law (BRASIL, 2002). Nonetheless, other narratives show conflicts as the narratives about some deaf people's families that do not know sign language or that know it poorly. We hope, with the discussion promoted based on the selected students' voices, to point out and observe these aspects so that they may subsidize, in future works, the search for ways of deployment of a bilingual education to the deaf.

Keywords: Written Portuguese for the deaf; Learning strategies; Linguistic policies.

\section{INTRODUÇÃO}

A afirmação que integra o título deste artigo foi retirada do texto de Priscilla Cavalcante, autora surda que assina um relato de experiência no presente dossiê da Revista X. A fala, na verdade, é de uma amiga de infância, ouvinte, de Priscilla. Como se pode notar ao longo de seu texto, Priscilla viveu parte de sua infância e de sua adolescência na década de oitenta no Brasil, período em que a Comunicação Total, doravante CT, encontrava seu auge na educação de surdos brasileira. Nesse momento, entretanto, havia, como ainda há, pensamentos e práticas ouvintistas ${ }^{3}$, evidenciadas fortemente à época do oralismo, subjacentes a falas, pensamentos e atitudes.

A filosofia oralista, em outras palavras, oralismo, considera que o desenvolvimento da fala está diretamente ligado ao desenvolvimento intelectual do surdo. Por essa razão, ressalta a surdez como deficiência e, por conseguinte, a visão clínico-terapêutica da surdez, segundo a qual o indivíduo possui uma patologia tratável através de mecanismos de aprendizagem da língua oral dominante (FERNANDES, 1999; MACHADO, 2006; SKLIAR, 1998). De acordo com esse modo de ver a surdez, a língua de sinais "deveria

\footnotetext{
${ }^{3}$ Para Skliar (1998, p. 15), o ouvintismo "é um conjunto de representações dos ouvintes, a partir do qual o surdo está obrigado a olhar-se e narrar-se como se fosse ouvinte".
} 
REVISTA X, Curitiba, volum e 13, n.1, p. 230-254, 2018.

Dossiê Especial: Português como Língua Adicional em contextos de minorias:

(co)construindo sentidos a partir das margens

BIZON \& DINIZ (Orgs.)

ser completamente banida para permitir o êxito no processo de oralização" (SILVA \& FAVORITO, 2009, p. 15). O foco educacional sobre a oralização das crianças surdas (POKER, 2013) com a utilização de "estratégias e recursos de cunho reparador, corretivo" (SILVA \& FAVORITO, 2009, p. 15) tinha entre seus objetivos o de produzir o que se pode denominar de normalização dos sujeitos. Assim sendo, toda e qualquer falha era atribuída aos indivíduos surdos e/ou a sua pouca ou nenhuma oralização.

A partir de 1960, no entanto, devido ao insucesso dos métodos orais, que não davam conta das questões escolares dos surdos (ibidem, p. 17), críticas significativas iniciaramse. Nos Estados Unidos, o linguista William Stokoe, em suas pesquisas sobre Língua Americana de Sinais (ASL), mostra que os sinais utilizados pelos surdos compõem, de fato, uma língua natural com as "mesmas características das línguas orais" (POKER, 2013, p.3), a saber, fonologia, morfologia, sintaxe (QUADROS \& KARNOPP, 2004), etc.

Foi neste cenário que surgiu o movimento da Comunicação Total (CT), o qual, no Brasil, repercutiu nos anos 80. Conforme esclarece Poker (2013, p. 6), a CT preocupa-se também com a aprendizagem da língua oral pela criança surda, mas acredita que os aspectos cognitivos, emocionais e sociais não devem ser deixados de lado só por causa da aprendizagem da língua oral. Defende assim a utilização de qualquer recurso espaço - visual como facilitador da comunicação (POKER, 2013, p. 6).

Dentre esses recursos, estão os de movimento, compostos por métodos combinados. Citam-se "o desenho, a escrita, a pantomima, a língua de sinais, a fala, o alfabeto manual, gestos naturais etc." (SILVA \& FAVORITO, 2009, p. 18). Além disso, havia métodos que utilizavam a língua de sinais

\begin{abstract}
obedecendo à ordem da língua oral (o português sinalizado, por exemplo) até seu uso com recursos importados das línguas orais, resultando em vários métodos que eram utilizados nas escolas, com maior ou menor adesão, com o objetivo de ensinar ao surdo a gramática da língua oral. Acreditava-se que a comunicação deveria ser privilegiada e não uma língua em particular (ibidem, p. 18-19).
\end{abstract}

A CT permitiu a reinserção do uso de sinais em sala de aula, embora fossem utilizados meramente como apoio à fala e os professores fizessem uso artificial ${ }^{4}$ da

\footnotetext{
${ }^{4}$ Entende-se por uso artificial um uso mecanizado e fragmentado de sinais da língua de sinais, não se constituindo no uso da língua de sinais propriamente dita.
} 
REVISTA X, Curitiba, volume 13, n.1, p. 230-254, 2018.

Dossiê Especial: Português como Língua Adicional em contextos de minorias:

(co)construindo sentidos a partir das margens

BIZON \& DINIZ (Orgs.)

língua de sinais (ibidem). Em resposta a este movimento, a partir dos anos 1990, emergiram propostas de educação bilíngue para surdos.

Na educação bilíngue, a LIBRAS é considerada a primeira língua (L1) e o português, nas modalidades oral e/ou escrita, a segunda (L2) (BRASIL, 2005) língua dessa comunidade, afirmando, portanto, a escolha pelo bilinguismo ${ }^{5}$. Para as escolas, porém, o modelo de Educação Bilíngue (FENEIS, 2011) proposto pela comunidade surda refere-se ao português escrito. De acordo com documento elaborado pela Federação Nacional de Educação e Integração dos Surdos (FENEIS),

\begin{abstract}
busca-se garantir a manutenção e criação de escolas que tenham como proposta educacional uma EDUCAÇÃO ESPECÍFICA, DIFERENCIADA, CULTURAL e BILÍNGUE para os Surdos brasileiros que têm a Língua de Sinais Brasileira como sua primeira língua e que ainda atenda e promova a inclusão social dos surdos na sociedade (ibidem, p. 1).
\end{abstract}

Esse movimento consolida a luta incessante e antiga da comunidade surda brasileira pela inclusão linguística de fato. Antes mesmo da Lei de LIBRAS (BRASIL, 2002) e do Decreto 5626 (BRASIL, 2005) ${ }^{6}$, os surdos já reivindicavam diversas mudanças em relação às suas comunidades. Exemplo disso é o documento intitulado "A educação que nós surdos queremos" (FENEIS, 1999) que influenciou o texto do Decreto 5626 (BRASIL, 2005). No documento, são reivindicadas escolas de surdos e, somente quando essas não forem possíveis, classes especiais para surdos, além de serem priorizados os profissionais surdos qualificados para o ensino de LIBRAS e a profissionalização do Instrutor de LIBRAS. Pelas razões históricas apresentadas previamente, no entanto, predominam representações equivocadas sobre os surdos, que prejudicam seu acesso à educação de qualidade e a outros direitos fundamentais no exercício da cidadania.

\footnotetext{
${ }^{5}$ Ressalta-se que bilinguismo e educação bilíngue são conceitos diferentes, embora tenha havido certa confusão na literatura sobre surdez. O bilinguismo, grosso modo, trata do uso de duas línguas. A educação bilíngue, por sua vez, ultrapassa essa visão. Na educação bilíngue para surdos, é desejado, além do uso das duas línguas, um conjunto de medidas outras, como a criação de materiais bilíngues, a formação de professores bilíngues e o ensino e a difusão da língua de sinais, para citar alguns pontos.

6 A Lei de LIBRAS (BRASIL, 2002) e o Decreto 5626 (BRASIL, 2005) são conquistas da luta da comunidade surda brasileira, ao longo de anos, pela legitimação e regulamentação da LIBRAS como língua de direito do indivíduo surdo brasileiro. São alguns exemplos de benefícios trazidos por essas conquistas o reconhecimento da LIBRAS como L1 e do português como L2 para surdos, além da inclusão da LIBRAS como disciplina curricular e da formação de profissionais de LIBRAS.
} 
REVISTA X, Curitiba, volume 13, n.1, p. 230-254, 2018.

Dossiê Especial: Português como Língua Adicional em contextos de minorias:

(co)construindo sentidos a partir das margens

BIZON \& DINIZ (Orgs.)

Considerando esse cenário, proponho, neste artigo, discutir como jovens estudantes surdos, pertencentes a gerações que vivenciam os resultados da luta política e linguística da comunidade surda desde o nascimento e/ou tenra idade, compreendem questões basilares da luta da comunidade surda brasileira em favor de um projeto de Educação Bilíngue para Surdos. Iniciado nos anos 1980 e fortalecido ao longo das últimas décadas, tal projeto institui, dentre outras premissas, o ensino da LIBRAS como primeira língua e o de português como segunda língua. Focalizo, para tanto, narrativas geradas em conversas em grupo e individuais realizadas com alunos do sexto e sétimo anos do Ensino Fundamental II de uma escola de surdos localizada no Rio de Janeiro. Visibilizando as narrativas desses estudantes, busco discutir os usos sociais da língua portuguesa em suas vidas e suas relações com pessoas ouvintes. Espera-se, com a discussão promovida a partir das vozes dos estudantes aqui focalizados, levantar e observar os pontos mencionados para que possam subsidiar, em trabalhos futuros, a busca de caminhos para a operacionalização de uma educação bilíngue para surdos.

\section{REFERENCIAL TEÓRICO}

Os dados em tela neste artigo fazem parte de um corpus maior produzido no âmbito de minha pesquisa de doutorado, em andamento ${ }^{7}$, que se afilia à Linguística Aplicada Indisciplinar (ou Crítica - LAC - ou, ainda, Transgressiva) em diálogo com estudos poscoloniais (CAVALCANTI, 2006). Pennycook (2006, p. 67) define a LAC

como uma nova forma de conhecimento interdisciplinar, prefer(indo) compreendê-la como uma forma de antidisciplina ou conhecimento transgressivo, como um modo de pensar e fazer problematizador. Isso quer dizer não somente que a LAC implica um modelo híbrido de pesquisa e práxis, mas também que gera algo que é muito mais dinâmico.

Como salientado por Moita Lopes, neste enredo de teorizações e não de respostas positivistas às questões de pesquisas, o "conhecimento que não considera as vozes daqueles que vivem a prática social não pode dizer nada sobre ela” (Ibidem, p. 101). De acordo com Santos (2004, p. 9, apud MOITA LOPES, 2006, p. 236),

\footnotetext{
7 Pesquisa de Doutorado em Linguística Aplicada iniciada em 2016 no Instituto de Estudos da Linguagem, Unicamp.
} 
REVISTA X, Curitiba, volume 13, n.1, p. 230-254, 2018.

Dossiê Especial: Português como Língua Adicional em contextos de minorias:

(co)construindo sentidos a partir das margens

BIZON \& DINIZ (Orgs.)

a perspectiva pós-colonial parte da ideia de que, a partir das margens ou das periferias, as estruturas de poder e de saber são mais visíveis. Daí o interesse desta perspectiva pela geopolítica do conhecimento, ou seja, por problematizar quem produz conhecimento, em que contexto o produz e para quem o produz.

Mais ainda, esta perspectiva é o espaço para desvelar olhares refratários do positivismo e de grupos dominantes ditos majoritários. É preciso levar em conta o ponto de vista dos atores, ou seja, daqueles que, muitas vezes, estão às margens ou nas periferias (CAVALCANTI, 2006). Na presente pesquisa, isso significa que os surdos são atores de sua própria história, como clama o movimento intitulado "Nada sobre nós sem nós" ${ }^{\text {, }}$ e que são protagonistas de seu bilinguismo e de sua proposta de educação bilíngue.

Vale sublinhar que o bilinguismo dos surdos está inscrito no contexto de minorias (CAVALCANTI, 1999; FAVORITO, 2006; MAHER, 1997, 2007). Segundo Cavalcanti, o bilinguismo está “estereotipicamente relacionado às línguas de prestígio no que se convencionou chamar de bilinguismo de elite" (1999, p. 387). Este é

um bilinguismo de escolha relacionado a línguas de prestígio tanto internacional quanto nacionalmente. As escolas bilíngues no Brasil (e em outros países), por exemplo, escola americana, escola francesa, têm na língua alvo seu (principal e, às vezes, único) meio de instrução independentemente da L1 do aluno (ibidem).

Por outro lado, "enquanto que para a maioria dos alunos das escolas brasileiras o bilinguismo é facultativo, para os alunos indígenas, surdos e de comunidades de imigrantes, o bilinguismo é compulsório” (MAHER, 2007, p. 68). Segundo Maher, “quando o que está em jogo são línguas de prestígio, o bilinguismo é sempre visto positivamente" (ibidem, p. 69). Entretanto, quando

uma das línguas envolvidas é avaliada como sendo não-prestigiosa, como é o caso, por exemplo, das línguas indígenas e da LIBRAS, o bilinguismo é quase sempre visto como um problema a ser erradicado (ibidem).

\footnotetext{
${ }^{8}$ Movimento defendido pela comunidade surda brasileira e que se apoia na Convenção dos Direitos das Pessoas com Deficiência. Prega que, para que algo seja decidido sobre os surdos, esse grupo deve ser consultado. Sua página na rede social Facebook encontra-se neste endereço: $<$ https://pt-br.facebook.com/pg/Movimento-Nada-Sobre-N\%C3\%B3s-Sem-N\%C3\%B3s528098007292922/community/>.
} 
REVISTA X, Curitiba, volume 13, n.1, p. 230-254, 2018.

Dossiê Especial: Português como Língua Adicional em contextos de minorias:

(co)construindo sentidos a partir das margens

BIZON \& DINIZ (Orgs.)

De acordo com Cavalcanti e Silva,

na escola brasileira, nunca houve, de fato, espaço para os alunos que falam um português que não seja o padrão, que podem ter problemas com a escrita em uma língua diferente da que falam/sabem. Nessa parcela da população estão os índios, os descendentes de imigrantes, os habitantes de cidades de fronteira e os surdos como minorias linguísticas (2007, p. 219).

O bilinguismo de minorias, portanto, denuncia o apagamento desses grupos. Ao contrário do bilinguismo de elite, o de minorias pressupõe uma série de estigmatizações acerca dos indivíduos envolvidos e suas línguas. Para Maher (2007, p. 71), “a primeira delas é que a língua minoritária vai dificultar, ou mesmo impedir, a aquisição da língua de prestígio". No caso dos surdos, isso embasa a visão, infelizmente corrente, de que a aprendizagem da LIBRAS prejudica a aprendizagem do português.

Segundo Cavalcanti (1999), o mito do monolinguismo, segundo o qual se acredita que um povo fala somente uma língua, desempenha papel importante nesse processo de apagamento e consequentes estigmatizações. De acordo com a autora,

para Wiley (1996:105): Em sociedades onde a maioria da população é monolíngue (...), há frequentemente uma suposição subjacente de que o monolinguismo (...) representa um estado ideal natural, enquanto o multilinguismo representa uma condição temporariamente anormal. No Brasil, a maioria da população é vista como monolíngue, (...) essa visão é artificial, porém extremamente eficaz para a imagem de estado ideal natural longe do "perigo" de qualquer condição temporariamente anormal proveniente de situações de bi/multilinguismo (ibidem, p. 397).

No caso dos surdos brasileiros, isso contribui para o apagamento de suas construções culturais e de sua língua por direito, estabelecida como tal na Lei $\mathrm{n}^{\circ} 10436$ (BRASIL, 2002). Sendo assim, o português e a LIBRAS disputam espaço e poder, o que caracteriza um bilinguismo diglóssico (FAVORITO, 2006; FERNANDES \& MOREIRA, 2009; MAHER, 1997). Nesse tipo de bilinguismo, "a comunidade usa uma língua (a de prestígio) para atividades públicas importantes e eventos sociais e outra para usos mais domésticos e íntimos (a sem prestígio)." (FERNANDES \& MOREIRA, 2009, p. 226). Por essa razão, no caso dos surdos, torna-se extremamente importante a distinção entre LIBRAS como L1 e português como L2.

Mais recentemente no Brasil, iniciou-se um movimento em prol das chamadas línguas adicionais. O termo língua adicional (e não língua estrangeira, segunda língua, terceira língua, etc.) denota “que esta língua nos pertence (não é algo estrangeiro a nós) 
REVISTA X, Curitiba, volume 13, n.1, p. 230-254, 2018.

Dossiê Especial: Português como Língua Adicional em contextos de minorias:

(co)construindo sentidos a partir das margens

BIZON \& DINIZ (Orgs.)

e que escolhemos adicionar essa língua ao nosso repertório para podermos usá-la para participar de práticas sociais" (KRAEMER, 2012, p. 12). Mais ainda, "a serviço da comunicação transnacional e/ou da participação cidadã contemporânea, a distinção entre nativo/estrangeiro ou primeira/segunda língua não é relevante" (SCHLATTER \& GARCEZ, 2009, p. 260). Para Schlatter e Garcez, falar em português língua adicional (PLA) parece mais significativo pelo "acréscimo que a disciplina traz a quem se ocupa dela, em adição a outras línguas que o educando já tenha em seu repertório" (ibidem, p. 127). Por repertório, entende-se, comumente, "uma forma de descrever como indivíduos implementam outros modos de comunicação em adição a suas múltiplas línguas/linguagens"9 (RHYMES, 2014, p. 3). Em outras palavras, as línguas não são estanques e os indivíduos não as aprendem, necessariamente, uma após a outra nem fazem uso de cada língua separadamente. Para Maher, por exemplo, a noção de bilinguismo equilibrado vem sendo questionada e o bilíngue de verdade, não idealizado, "não exibe comportamentos idênticos na língua X e na língua Y" (MAHER, 2007, p. 73). Para a autora, "um 'bom' bilíngue transita de uma língua para outra justamente porque, diferente do monolíngue, tem competência para tanto" (ibidem, p. 75).

Assim sendo, parece relevante adotar esta concepção no que tange à surdez. Ao se considerar o português para surdos como língua adicional, não se pretende tratar o português como língua acessória (interpretação desavisada que pode ser gerada pelo termo "adicional"). Pretende-se, sim, tratar das realidades linguísticas diversas dos surdos tanto em LIBRAS quanto em português. Em muitos casos, torna-se impossível precisar qual língua foi aprendida primeiro já que o bilinguismo dos surdos não se desenvolve do mesmo modo de outros grupos sociais. Dessa forma, não há garantia de que os surdos vão aprender LIBRAS ao nascerem e/ou ao longo de sua infância. A maioria nasce em famílias ouvintes que não sabem LIBRAS e que são orientadas por uma grande parte dos profissionais da saúde a investir em aquisição oral do português somente e em aparelhos auditivos e implantes cocleares.

Decorre então que a maioria esmagadora dos surdos é exposta a uma língua oral incipiente, e não à língua de sinais, de forma que muitos chegam à idade adulta ainda

\footnotetext{
${ }^{9}$ Todas as traduções são de minha responsabilidade.
} 
REVISTA X, Curitiba, volum e 13, n.1, p. 230-254, 2018.

Dossiê Especial: Português como Língua Adicional em contextos de minorias:

(co)construindo sentidos a partir das margens

BIZON \& DINIZ (Orgs.)

em momentos iniciais em seu continuum de aprendizagem das duas línguas. Por essas razões, a presente pesquisa adota o termo português segunda língua para surdos por entender a importância da terminologia utilizada na Lei de LIBRAS (BRASIL, 2002) e no Decreto 5626 (BRASIL, 2005). Esta escolha pauta-se no receio de enfraquecimento da luta da comunidade surda brasileira pela LIBRAS como L1 e o português como L2. Registre-se, no entanto, a afiliação à concepção de português como língua adicional, não mais nem menos importante do que a LIBRAS ${ }^{10}$, ao compor o repertório linguístico do indivíduo surdo. Além disso, é importante ressaltar o direito do surdo a ter acesso à LIBRAS como a língua de desenvolvimento cognitivo, afetivo, pessoal, subjetivo e ao português para que ambas componham seu repertório e suas práticas sociais.

Outro conceito relevante para o presente artigo é a visão de língua como discurso. Alinhando-me à De Fina (2011, p.1), afirmo que discurso refere-se "à língua em uso como formas organizadas e culturalmente moldadas de falas embutidas em práticas sociais concretas", bem como a "formas de representação da realidade e (...) de interagir linguisticamente". Nessa perspectiva, é relevante lembrar que, com o desenvolvimento do pensamento pós-moderno e pós-estruturalista, a língua passou a ser compreendida

como um recurso que as pessoas utilizam e recriam constantemente, junto a outros recursos semióticos, para alcançar seus objetivos comunicativos (...), como formas fluidas, dinâmicas de comunicação [que] têm sido criadas ao longo dos milênios de existência humana e têm sido, então, moldadas e remoldadas através das práticas comunicativas em que as pessoas se engajam" (CAVALCANTI \& MAHER, 2018, p. 1).

Isso significa dizer que língua é prática e discurso e que toda e qualquer interação social cumpre com objetivos comunicativos, fato que nos remete aos dois pontos que serão analisados no presente artigo: os usos sociais da língua portuguesa na vida dos surdos participantes da pesquisa e suas relações com pessoas ouvintes.

Reafirmo a importância de se visibilizar os posicionamentos dos estudantes a respeito dessas questões, dada a impossibilidade de se pensar em um ensino específico da língua portuguesa no contexto da surdez sem tornar esses usos e essas relações parte integrante desse ensino.

\footnotetext{
${ }^{10}$ Refiro-me ao direito do indivíduo surdo, garantido em lei (BRASIL, 2002), à aprendizagem das duas línguas: a LIBRAS como sua primeira língua e, portanto, sua língua de constituição; e o português, como segunda língua, como meio de inserção perante à sociedade ouvinte dominante.
} 
REVISTA X, Curitiba, volume 13, n.1, p. 230-254, 2018.

Dossiê Especial: Português como Língua Adicional em contextos de minorias:

(co)construindo sentidos a partir das margens

BIZON \& DINIZ (Orgs.)

\section{CENÁRIO E METODOLOGIA DE PESQUISA}

Como já mencionado, neste artigo trago um pequeno recorte de registros gerados no âmbito da pesquisa de Doutorado em Linguística Aplicada, iniciada em 2016, no Instituto de Estudos da Linguagem da Universidade Estadual de Campinas, cujo objetivo central é compreender como estudantes surdos narram o papel do português em seus cotidianos e as experiências de aprendizagem dessa língua em contexto formal de ensino. Busca-se, com a problematização dessas narrativas, discutir a operacionalização de estratégias específicas para uma educação bilíngue para surdos como forma de potencializar a aprendizagem da língua portuguesa e, consequentemente, a inserção desses indivíduos na sociedade dominante.

No recorte trazido neste artigo, focalizo narrativas de estudantes surdos provenientes de conversas informais que exploraram dois tópicos de discussão já citados anteriormente: os usos sociais da língua portuguesa na vida dos estudantes e as relações desses estudantes com pessoas ouvintes. Reafirmo que, a meu ver, conhecer tais usos e explorá-los deve ser parte efetiva da construção de estratégias para o ensino nesse contexto.

Tais registros foram gerados em junho de 2017 em uma escola bilíngue para alunos surdos, com sede no Rio de Janeiro. A instituição conta com os segmentos Infantil, Fundamental I e Fundamental II, além de um Departamento de Ensino Superior e de setores relacionados ao atendimento à comunidade, como o de Fonoaudiologia, por exemplo. Os estudantes focalizados nesta pesquisa pertencem a turmas do sexto e do sétimo anos do Ensino Fundamental II. Essa escolha se deve ao fato de considerar que esses anos são fundamentais para a consolidação da aprendizagem da língua portuguesa pelo aluno surdo, dado que é uma nova etapa que se inicia na escolarização ${ }^{11}$, a qual vai apresentar o jovem a importantes questões de linguagem e de normas da própria escolarização que lhe serão exigidas ao longo de toda sua vida escolar. A inclusão dos alunos do sétimo ano nas conversas dá-se pelo fato de, na tese, buscarem-se suas

\footnotetext{
${ }^{11}$ É o momento de saída do Ensino Fundamental I e ingresso no Ensino Fundamental II.
} 
REVISTA X, Curitiba, volum e 13, n.1, p. 230-254, 2018.

Dossiê Especial: Português como Língua Adicional em contextos de minorias:

(co)construindo sentidos a partir das margens

BIZON \& DINIZ (Orgs.)

análises sobre o sexto ano, foco da pesquisa, além de se delinear aquilo que foi mais significativo, em relação ao sexto ano, como pista para a discussão sobre as estratégias.

A faixa etária desses jovens, doze mulheres e quinze homens, varia entre treze e vinte e três anos. Se pensarmos que estamos falando de turmas que não são, a priori, voltadas ao público de jovens e adultos (EJA), percebemos a discrepância entre as idades consideradas ideais para cada ano, onze e doze, respectivamente, e as reais idades dos participantes. Isso demonstra o grande atraso escolar de jovens surdos pela falta de preparo do nosso sistema de ensino para com esses alunos.

Quanto à escolaridade, as realidades são bem distintas. Há alunos que estudaram: em uma escola de CT famosa entre os surdos do Rio de Janeiro; em escolas municipais: com intérpretes, sem intérpretes, com professores que sabiam algo de LIBRAS, com turma de surdos; em escola estadual; em associações de surdos, nem sempre com intérpretes; em uma escola bilíngue para surdos em São Paulo; na própria instituição sede da pesquisa.

Para cada turma, duas de sexto e duas de sétimo, foram realizadas conversas individuais em um primeiro encontro e conversas posteriores em grupo, em dois dias distintos. Todas as conversas foram vídeo-gravadas em LIBRAS e, num segundo momento, traduzidas para a língua portuguesa escrita por intérpretes proficientes em LIBRAS.

No primeiro dia, para as conversas em grupo, foi apresentado um elemento provocador para cada turma: a imagem de um homem que segurava um papel com a palavra "Português"12, para o sexto, e um dicionário ${ }^{13}$ para o sétimo. Seguiram-se perguntas previamente planejadas acompanhadas de outras formuladas durante a conversa. Para a conversa individual, foi mostrado um vídeo, gravado com uma professora surda, que continha perguntas mais específicas sobre suas histórias individuais. No segundo dia das conversas em grupo, o procedimento foi o mesmo,

\footnotetext{
12 Disponível em: <http://www.istockphoto.com/br/foto/crian\%C3\%A7a-segurando-placa-comportugu\%C3\%AAs-pala vra-portugu\%C3\%AAs-portugu\%C3\%AAs-gm471063108-62567982? esource=A FF_IS_IR_SP_Free Ima ges _24619 5 \&asid=FreeImages\&cid=IS\&irgwc=1> Acesso em: janeiro/2017.

${ }^{13}$ Disponível em: <http://pt.freeimages.com/photo/dictionary-1427582> Acesso em: janeiro/2017.
} 
REVISTA X, Curitiba, volume 13, n.1, p. 230-254, 2018.

Dossiê Especial: Português como Língua Adicional em contextos de minorias:

(co)construindo sentidos a partir das margens

BIZON \& DINIZ (Orgs.)

entretanto, o elemento motivador de cada ano foi diferente: o vídeo "A menina que odiava livros"14 (até 2’40), para o sexto, e "Livro 3D Animação"15 para o sétimo.

Na pesquisa, utilizo as narrativas como aparato teórico para a geração de registros, pois, alinhada a De Fina e Baynham (2001, p. 1), compreendo que "os proponentes dos turnos narrativos enfatizam a importância da pesquisa qualitativa como uma forma de entender fenômenos sociais", conferindo aos que narram a "possibilidade de serem ouvidos". Mais ainda, para Wortham, os narradores posicionam-se em diálogo contínuo com outros falantes, construindo-se interacionalmente (2001, p. 1). Entende-se por outros falantes, na esfera física da sala de aula onde foram gravadas as conversas, os outros alunos, a intérprete e a professora pesquisadora. Segundo Maher (2010, p. 39),

\begin{abstract}
o pesquisador não registra, simplesmente, o que as pessoas dizem. Nós somos agentes cruciais na micropolítica de elicitação de dados porque nossa própria presença determina, mesmo que em parte, o que os sujeitos pesquisados nos dizem. Além disto, nossa seleção do que é relevante para análise, assim como essa em si, estão contaminadas pela nossa história pessoal, por nosso posicionamento ideológico.
\end{abstract}

Na função moderadora, o pesquisador introduz o assunto, propõe questões, ouve e busca garantir a equidade de participação (GATTI, 2012, p. 29). Assumi, portanto, essa postura nas conversas com o objetivo de garantir não só a equidade, mas também um ambiente propício à (re) construção de nós mesmos através das narrativas.

\title{
“AH...PORTUGUÊS É ... IGUAL FALAR EM LIBRAS": FOCALIZANDO AS NARRATIVAS DOS ALUNOS SURDOS
}

A instituição representa para esses alunos um lugar de encontro de pares surdos e de fluidez maior de comunicação em relação às escolas anteriores e às suas famílias. Nas narrativas dos estudantes, há menções sobre o momento em que chegaram à escola de surdos e sobre como se sentiram, além de relatos sobre como a comunicação flui melhor na escola em que estudam. São exemplos:

\footnotetext{
${ }^{14}$ Disponível em: <https://www.youtube.com/watch?v=ZsURXKum5K0> Acesso em: janeiro/2017.

${ }^{15}$ Disponível em: <https://www.youtube.com/watch?v=8RyJSTpJHos> Acesso em: janeiro/2017.
} 
REVISTA X, Curitiba, volume 13, n.1,p.230-254, 2018.

\section{Dossiê Especial: Português como Língua Adicional em contextos de minorias: (co)construindo sentidos a partir das margens BIZON \& DINIZ (Orgs.)}

Lucas $^{16}$ : Quando ela [a mãe] dispara a falar, eu falo: "Peraí! Devagar!" Aí, então, consigo ler os lábios e entender. (...) Chegando no (nome da escola de surdos), comecei a aprender a me comunicar em língua de sinais assim como os outros alunos. Senti facilidade.

Julieta: Eu prefiro o [nome da escola de surdos]. Considero melhor do que outro lugar. (...) Recebo ajuda e explicações mais claras. Entendo mais claramente. Lá fora a falta de comunicação atrapalha. É difícil. Aqui é bem melhor. Tudo fica mais claro pra mim.

Ubaldo: Acho o [nome da escola de surdos] bom porque entendo as explicações em língua de sinais. Leio. Lá fora... é muito mais difícil! Porque eles ficam mexendo a boca, falando com a gente.

César: Eu gosto daqui do [nome da escola de surdos]. Acho muito legal! Estudar é importante para aprender. É importante tirar as dúvidas. Lá fora é difícil! A comunicação não rola. Eu até tento, mas sem sucesso. É isso aí.

Elisa: O [nome da escola de surdos] é melhor! Lá fora não aprendi nada! Fiquei prejudicada! No [nome da escola de surdos], eu aprendi, me desenvolvi.

Julieta: Lá fora o aprendizado fica atrasado.

Gil: É.... A gente perde muito.

Em outras palavras, embora haja algum tipo de comunicação com as famílias e em outras escolas, os jovens relatam preferir, aprender mais e melhor e sentir mais facilidade na escola bilíngue de surdos em razão do conforto trazido pelo uso da língua de sinais.

Ademais, para quatro participantes, a escola de surdos foi o lugar de aprendizagem da LIBRAS. Para todos, mesmo para os que tiveram algum tipo de contato anterior com a LIBRAS, a escola representa também o lugar de desenvolvimento da língua de sinais, como demonstram os seguintes excertos:

Ubaldo: Eu tinha 12 anos de idade. Entrei aqui em 2006, sem saber nada. Me perguntavam os sinais e eu não sabia nenhum. Foi quando fui para uma sala e o professor da turma pediu minha opinião sobre um sinal para me batizar. (...) Ele perguntou se eu queria que ele me ensinasse. Falei: "Vamos!" Aí, pouco a pouco, ele foi me ensinando os sinais, as palavras... (...) Então, estava com 12 anos e em 2 meses já estava sinalizando com agilidade. Assim já estava progredindo.

${ }^{16}$ Todos os nomes são fíctícios. 
REVISTA X, Curitiba, volume 13, n.1, p. 230-254, 2018.

Dossiê Especial: Português como Língua Adicional em contextos de minorias:

(co)construindo sentidos a partir das margens

BIZON \& DINIZ (Orgs.)

Renata: Dificilmente usava a língua de sinais. Eu olhava as pessoas. Conheci os colegas e falava oralmente seus nomes. Porque eu não sabia os sinais, então, falava. Falava para dizer minha idade: "Tenho 17 anos" (...) Eu tive dificuldade com a língua de sinais. Nunca tinha visto o [nome da escola de surdos].

Embora Renata relate um estranhamento inicial com a língua de sinais, decorrente do fato de ter sido única e exclusivamente oralizada até sua entrada na escola de surdos, ela também relata sua atual necessidade de uso da LIBRAS:

Renata: Na minha opinião, está faltando fazer provas em língua de sinais. (...) Só oralizando, não consigo entender nada.

Para uma aluna específica, a instituição representa também o rompimento com o preconceito que ela sofria, por ser surda, na escola anterior.

Cândida: Tive problemas de ofensas que me deixavam deprimida. Aí falei pra minha mãe que eu não gostava (...). Então voltei para o [nome da escola]. Foi bom! Me animei porque parecia que eu já conhecia os amigos com os quais me relacionava na Educação Infantil. Eu tinha 4 anos de idade.

Em relação à aprendizagem da língua de sinais, podemos afirmar que nenhum aluno, até esse momento da pesquisa, relatou ter sido exposto à sua língua de direito desde o nascimento. Todos relatam ter aprendido a língua na escola e/ou com alguém de suas famílias, geralmente a mãe, ou amigos a partir de idade escolar. Existem casos de alunos que aprenderam LIBRAS aos onze anos, entretanto. ${ }^{17}$ Ressalto o papel fundamental da escola, principalmente da instituição em questão enquanto escola bilíngue para surdos, na aprendizagem e no desenvolvimento da LIBRAS. Com exceção de quatro alunos, todos os outros conheceram a língua de sinais na escola.

Quanto à comunicação em família, com exceção de uma aluna, que é a única pessoa a sinalizar na casa em que vive, todos os outros relatam que as pessoas que compõem seu núcleo familiar mais próximo, como pais, mães, padrastos, madrastas, irmãos e irmãs, sabem um pouco de LIBRAS, embora alguns também relatem a falta de conhecimento da língua. São exemplos:

\footnotetext{
${ }^{17} \mathrm{Na}$ tese em desenvolvimento, são explicitadas e discutidas mais informações sobre os contatos iniciais dos estudantes com a LIBRAS.
} 
REVISTA X, Curitiba, volume 13, n.1, p. 230-254, 2018.

Dossiê Especial: Português como Língua Adicional em contextos de minorias:

(co)construindo sentidos a partir das margens

BIZON \& DINIZ (Orgs.)

João: A minha mãe é intérprete. Ensinou-me e eu aprendi com a idade a sinalizar rápido.

Tatiana: [Sobre a mãe] Não sabe tudo, não. Sabe mais ou menos usar as expressões faciais e corporais. Minha mãe já foi no curso de LIBRAS. Já leu livros lá no curso. (...) Meu pai mora lá em [bairro do Rio de Janeiro]. Ele sabe LIBRAS. Sabe LIBRAS e expressões faciais e corporais.

Márcia: O meu pai não sabe nada de LIBRAS. (...) Meu padrasto sabe LIBRAS.

No entanto, quando perguntados sobre a comunicação com outros parentes, os estudantes indicaram a falta de conhecimento da língua de sinais por parte dessas pessoas. São poucos os que sabem algo de LIBRAS, como relatam Lucas e Márcia:

Lucas: Minha família não sabe LIBRAS. Só tem ouvintes. São todos ouvintes.

Márcia: Na família da minha mãe, alguns sabem um pouco. Outros não sabem e não entendem nada.

Essa comunicação, porém , conforme indicam Jair e Laís, é incipiente, pois eles precisam recorrer à oralização, à escrita do português, a expressões faciais, a gestos, a mímicas e a aplicativos de LIBRAS no tablet:

Jair: Escrevem, usam o tablet para falar comigo. Dá pra entender.

Laís: (...) eu tenho que ter paciência com meu pai. Ele fica mexendo a boca pra falar comigo. Tenho que oralizar. Lembrei que também uso a escrita com ele. (junho/2017)

Em relação ao trânsito entre línguas ${ }^{18}$, os participantes relatam, com exceção de dois que utilizam e/ou preferem somente a LIBRAS, que utilizam LIBRAS e português oral e/ou escrito com suas famílias e com ouvintes em geral. Seis participantes demonstraram o trânsito entre as línguas durante as interações nas conversas individuais, a saber: mesmo sinalizando na maior parte do tempo, em alguns momentos, oralizaram sem sinalizar e, em outros, sinalizaram e oralizaram ao mesmo tempo. São exemplos as observações das intérpretes entre parênteses:

\footnotetext{
${ }^{18}$ Refiro-me ao uso de uma e/ou outra língua durante as interações comunicativas.
} 
REVISTA X, Curitiba, volume 13, n.1, p. 230-254, 2018.

Dossiê Especial: Português como Língua Adicional em contextos de minorias:

(co)construindo sentidos a partir das margens

BIZON \& DINIZ (Orgs.)

Gil: Estudei português, aprendi a escrever, a escrever, também... é... [risos].. palavras, é... estudei palavras... é igual falar $($ ORALIZANDO $) \ldots$

Geise: [Sobre ter estudado em escola estadual] (EXPRESSÃO $E$ MOVIMENTO DE NEGAÇÃO COM A CABEÇA) Nunca (RESPONDEU COM A BOCA E NÃO COM AS MÃOS).

Lucas: [Sobre o sinal de "língua", o qual a pesquisadora não se lembrava] Língua. $(O$ ALUNO CONFIRMOU O SINAL ORALIZANDO E SINALIZANDO)

Durante a análise parcial dos dados gerados, pude constatar que, no geral, os participantes apresentam avaliações positivas em relação ao aprendizado da língua portuguesa. A fala de Laís é demonstrativa dessa constatação:

Laís: é importante estudar língua portuguesa e também é muito importante aprender, observar, entender, ter interesse e o mais importante é ter interesse nesta língua.

Na fala de Gil, um jovem oralizado que aprendeu LIBRAS tardiamente, percebese que tal avaliação positiva vem acompanhada de avaliação positiva acerca da LIBRAS, posicionando as duas línguas estão em pé de igualdade:

Gil: Ah... português é importante... (O ALUNO FAZ O SINAL DE "PRECISAR") é igual falar em LIBRAS.

Para Gil, as duas línguas são línguas. Embora esta afirmação possa parecer redundante, torna-se imprescindível em um cenário em que, até bem pouco tempo, a língua do surdo não era nem mesmo reconhecida como língua. Talvez esta seja uma característica de uma geração de surdos que tem sua língua de direito garantida e que, por conseguinte, tem muito mais chances de acesso à LIBRAS do que as gerações anteriores. Embora saibamos que a maioria dos surdos não tem acesso à aprendizagem da LIBRAS desde cedo, é importante salientar que esta é a língua de direito do surdo brasileiro, direito este garantido em lei (BRASIL, 2002). Em algumas pesquisas (RODRIGUES, 2013), já se observam, por exemplo, relatos de surdos sobre a importância de se aprenderem as duas línguas, fato que se distancia dos discursos inflamados e acalorados, e que estão no inconsciente dos que vivenciaram fortemente os 
REVISTA X, Curitiba, volume 13, n.1, p. 230-254, 2018.

Dossiê Especial: Português como Língua Adicional em contextos de minorias:

(co)construindo sentidos a partir das margens

BIZON \& DINIZ (Orgs.)

$\operatorname{conflitos}^{19}$, nos tempos de auge do oralismo, de muitos que inferiorizavam o português na tentativa de legitimação da língua de sinais e de outros muitos que inferiorizavam a LIBRAS na tentativa de manutenção do português como língua de poder.

A seguir, a fala de Tatiana, aproximando-se da fala anterior de Gil, demonstra a consciência de que a LIBRAS é uma língua e de que o que ela usava antes de aprender a língua era uma comunicação caseira:

Tatiana: Em casa, quando eu era pequena, eu não sabia LIBRAS e fazia água (FALOU E USOU UM GESTO DE BEBER COM O POLEGAR EM DIREÇÃO À BOCA) para a minha mãe. Fui aprendendo, era engraçado, depois o sinal de água e outros. Eu sempre fiz "comida" igual ao sinal de comer.

Como se pode perceber, ela distingue o que parece considerar um gesto para "beber água", utilizado por ela quando ainda não sabia LIBRAS, do sinal próprio da língua de sinais. Em outras palavras, ela parece avaliar a LIBRAS como língua diferente da comunicação que usava em casa antes de aprender os sinais.

Nesse sentido, as relações desses alunos com pessoas ouvintes também parecem demonstrar a tentativa de negociação de sentidos (SALES et al., 2004) sem, contudo, simbolizar relações traumáticas, como as geradas pelo ouvintismo (ver nota de rodapé 2) todo o tempo, o que se vê nos relatos a seguir:

Eduardo: Já, já, no passado, antigamente mostrava um papel para alguém na rua e a pessoa mostrava um caminho errado, diferente, a pessoa escrevia e mandava para outro lugar e eu falava, tudo bem e devolvia o papel para a pessoa e ela olhava e apontava que era para ir para lá eu ia para o local.

Adriel: Nós combinamos a melhor forma de comunicação.

Embora haja desentendimentos por conta da comunicação, Eduardo e Adriel não proferiram ideias negativas sobre a situação. Acredito fortemente que isso decorra da luta política e linguística dos surdos que têm tido conquistas significativas. Seria ingenuidade afirmar que não há disputa entre as línguas, entretanto, o direito à LIBRAS

\footnotetext{
${ }^{19}$ Ressalte-se que os conflitos persistem. O que parece haver é um arrefecimento, por parte de muitos, que parecem sentir que o lugar da língua de sinais está posto apenas com a criação da lei (BRASIL, 2002) e do Decreto (BRASIL, 2005).
} 
REVISTA X, Curitiba, volume 13, n.1, p. 230-254, 2018.

Dossiê Especial: Português como Língua Adicional em contextos de minorias:

(co)construindo sentidos a partir das margens

BIZON \& DINIZ (Orgs.)

como língua está garantido em lei, o que parece se refletir em falas como a de Tatiana quando perguntada sobre como se sentia em suas interações com pessoas ouvintes:

Tatiana: Normal...me sinto feliz (...) as pessoas às vezes não sabem LIBRAS, coitadas....

Em outras palavras, a falha na comunicação com pessoas ouvintes não parece causar infelicidade. Ao contrário, as pessoas que não sabem LIBRAS são tratadas como “coitadas", inversão total da visão clínico-terapêutica da surdez em que os surdos são os deficientes. Essa fala, além disso, dialoga com o título deste artigo. Depois de todas as conquistas da comunidade surda brasileira, há espaço para que uma pessoa surda tenha pena de ouvintes que não sabem LIBRAS e para que uma ouvinte, a amiga de Priscilla no relato de experiência que precede este artigo, lamente o fato de sua amiga surda nunca ter lhe ensinado a língua de sinais.

Por outro lado, ainda se percebem muitas falas que buscam romper com os estigmas a que os surdos vêm sendo expostos ao longo da história (MAHER, 2007; SILVA \& FAVORITO, 2009). Isso se verifica nas falas de Adriel e de Abel:

Adriel: Eu sei mandar mensagem pelo celular, digo que sou surdo, mas que tenho uma cabeça normal.

Abel: Sou capaz.

As narrativas também trouxeram pistas sobre os usos sociais que a língua portuguesa apresenta nas vidas dos participantes. De modo geral, eles utilizam o português escrito para se comunicarem com ouvintes nas ruas, no comércio, no transporte público. Basicamente, eles pedem informações, compram produtos ou precisam se comunicar em emergências. Neste ponto, apresentam-se duas situações. A primeira diz respeito ao fato de os próprios surdos escreverem no papel. Já a segunda, corresponde a um ouvinte escrevendo o que precisa ser transmitido e o surdo apenas mostrando o papel. São exemplos:

Márcia: Um dia eu estava escrevendo uma lista e minha mãe me ajudou, escreveu e eu aprendi novas palavras. Então a minha mãe deixa que eu vá comprar pão e alguma coisa e vou sozinha na rua, caminhando e quando chego no local, mostro para a pessoa a lista e a pessoa me entrega o que tem na lista e eu dou o dinheiro 
REVISTA X, Curitiba, volume 13, n.1, p. 230-254, 2018.

Dossiê Especial: Português como Língua Adicional em contextos de minorias:

(co)construindo sentidos a partir das margens

BIZON \& DINIZ (Orgs.)

Laís: Ela [a mãe] já escreveu um papel e deixou tudo anotado para se acontecer alguma coisa ter como avisar senão ela fica muito, muito preocupada se eu passar mal na rua e se acontecer alguma coisa.

Os estudantes também disseram utilizar português escrito e/ou oral em casa com suas famílias que, em sua maioria, sabem pouca LIBRAS, o que se evidencia na fala de Jair:

Jair: Escrevem, usam o tablet para falar comigo. Dá pra entender.

O uso que parece, contudo, apresentar-se de forma mais fluida são as interações na internet através de sites de relacionamento e aplicativos, como informam Márcia e Eduardo:

Márcia: [A compreensão] Depende de algumas palavras, se me mostram algumas coisas no Whatsapp.

Eduardo: Algumas coisas que leio no Facebook, no Twitter.

Os jovens também disseram utilizar a internet para estudar/pesquisar, como explicitado na fala de Julieta:

Julieta: Quando estou escrevendo no Facebook e percebo que estou usando uma palavra inadequada que eu sei que um ouvinte não vai entender, eu lanço no Google Tradutor e vejo que quase acerto a estrutura. Pego seu contexto certo e uso. Quando eu vejo que errei, uso este recurso. Aí eu entendo.

Dois dos participantes também apontaram que era importante escrever português para arrumar namorado (a) e para marcar encontros:

Laís: Comunicar e tal... Risos. É uma ideia! Saber escrever em português para arrumar namorado! Risos

Luan: Também posso combinar um encontro com a namorada, escrevo em um papel marcando o encontro...

Como se pode perceber, as narrativas dos alunos fornecem pistas que já permitem compreender, pelo menos parcialmente, as questões abordadas neste artigo, a saber, os usos sociais que fazem da língua portuguesa e suas relações com pessoas ouvintes, as quais, acredito, são significativas para uma proposta de educação bilíngue 
REVISTA X, Curitiba, volume 13, n.1, p. 230-254, 2018.

Dossiê Especial: Português como Língua Adicional em contextos de minorias:

(co)construindo sentidos a partir das margens

BIZON \& DINIZ (Orgs.)

condizente com a proposta elaborada pela comunidade surda (FENEIS, 2011). Somado a isso, essas narrativas também demonstram, como vimos em alguns excertos, indícios de que esses alunos tratam alguns pontos, como o uso do português oral e/ou escrito, por exemplo, de forma não tão traumática quanto os surdos que vivenciaram as práticas ouvintistas que eram amplamente empregadas durante o oralismo e a comunicação total. ${ }^{20}$ Esses alunos, porém, demonstram a manutenção e o fortalecimento de suas identidades surdas quando, por exemplo, assumem o papel significativo das duas línguas em seus repertórios linguísticos e assumem a LIBRAS como sua língua de direito, de formação e de constituição subjetiva.

\section{CAMINHOS EM CONSTANTE (RE) CONSTRUÇÃO}

O título do presente artigo, como vimos anteriormente, remete-nos à fala de uma amiga ouvinte de Priscilla, amiga de infância, sobre o fato de ela nunca lhe ter ensinado a língua de sinais. Com base em todo o histórico presente nesse artigo, podemos interpretar essa fala de algumas formas. Primeiro, podemos relacionar o fato de Priscilla não ter ensinado LIBRAS à amiga à época em que viveu sua infância. Priscilla experienciou o auge da CT, como descreve em seu relato, época em que qualquer forma de comunicação era privilegiada e não necessariamente a língua de sinais. Segundo, na década de 80, a língua brasileira de sinais ainda não havia sido considerada língua de direito da comunidade surda do país. A Lei de LIBRAS só foi finalizada após inúmeros embates políticos e linguísticos, como vimos, em 2002 e o Decreto 5626, em 2005, duas décadas depois.

A fala de sua amiga, no entanto, mostra que, na fase adulta, essa amiga buscou um curso de LIBRAS e aprendeu a língua de sinais, lamentando o fato de Priscilla nunca lhe ter ensinado formalmente os sinais. Relaciono essa fala às conquistas da comunidade surda brasileira. Como vimos, antes mesmo da Lei (2002) e do Decreto

\footnotetext{
${ }^{20}$ Lembro que ainda há práticas ouvintistas. No entanto, depois de todas as conquistas da comunidade surda, essas práticas são mais veladas.
} 
REVISTA X, Curitiba, volume 13, n.1, p. 230-254, 2018.

Dossiê Especial: Português como Língua Adicional em contextos de minorias:

(co)construindo sentidos a partir das margens

BIZON \& DINIZ (Orgs.)

(2005), havia textos sendo publicados pela comunidade que defendiam os interesses dos surdos e em prol de uma educação bilíngue para essas pessoas. Exemplo disso, como já apontado, é o documento “A educação que nós surdos queremos” (FENEIS), de 1999.

Até o momento, as narrativas dos alunos parecem reafirmar o fato de que as gerações que vivenciaram, e ainda vivenciam, as transformações políticas e linguísticas citadas neste artigo apresentam posicionamentos diferenciados, em relação às questões analisadas, daqueles apresentados por gerações anteriores (FAVORITO, 2006). As posições dos alunos em relação ao português e à sua aprendizagem são positivas. Eles utilizam a língua para funções sociais como a comunicação em família, através de oralização e/ou texto escrito; a comunicação com pessoas ouvintes nas ruas, tanto para compras quanto para a comunicação instantânea; a comunicação com seus amigos, ouvintes e surdos, nas redes sociais; dentre outras. Parece também estar posto para esses participantes o status de língua de direito e de construção de subjetividades da LIBRAS em suas vidas e do português como segunda língua. Por essa razão, as relações com pessoas ouvintes não parecem mais tão traumáticas quanto às de gerações anteriores.

Pretende-se que os pontos analisados neste artigo subsidiem, em trabalhos futuros, as discussões em prol de uma educação bilíngue para surdos em que os surdos sejam protagonistas de sua própria história (CAVALCANTI, 2006).

Toda a política desenvolvida até o momento parece estar, de fato, impulsionando movimentos em direção a deslocamentos significativos. Para tal, entretanto, é preciso que a comunidade surda continue sua luta sistematicamente. As línguas sempre disputarão espaço e poder e a comunidade surda não deve permitir, acredito, que a falsa ideia de harmonia linguística enfraqueça a luta nem permita atitudes ouvintistas travestidas de preocupação. A luta não está, de forma alguma, vencida.

\section{REFERÊNCIAS}

BRASIL. Lei 10.436, de 24 de abril de 2002. Brasília, DF. Disponível em: $<$ http://www.planalto.gov.br/ccivil_03/leis/2002/110436.htm >. Acesso em: 31 jun. 2018. 
REVISTA X, Curitiba, volume 13, n.1, p. 230-254, 2018.

Dossiê Especial: Português como Língua Adicional em contextos de minorias:

(co)construindo sentidos a partir das margens

BIZON \& DINIZ (Orgs.)

Decreto-lei no 5.626, de 22 de dezembro de 2005. Brasília, DF. Disponível em: $<$ http://www.planalto.gov.br/ccivil_03/_ato2004-2006/2005/decreto/d5626.htm >. Acesso em: 31 jun. 2019.

BIZON, A. C. C. Narrando o exame Celpe-Bras e o convênio PEC-G: a construção de territorialidades em tempos de internacionalização. Campinas, 2013. Tese de Doutorado. Instituto de Estudos da Linguagem, UNICAMP. Disponível em:

< http://repositorio.unicamp.br/jspui/handle/REPOSIP/269528 >. Acesso em: 06 mar. 2018 .

CAVALCANTI, M.C. Estudos sobre educação bilíngue e escolarização em contextos de minorias linguísticas no Brasil. D.E.L.T.A., v. 15, n. especial, p. 385-417, 1999.

Um olhar metateórico e metametodológico em pesquisa em linguística aplicada: implicações éticas e políticas. In: MOITA LOPES, L. P. (org.) Por uma linguística aplicada indisciplinar. São Paulo: Parábola, 2006. $1^{\text {a }}$ ed. $3^{\text {a }}$ reimpressão.

MAHER, T. M. Contemporary Brazilian Perspectives on Multilingualism: an introduction. In: CAVALCANTI, M. C.; MAHER, T. M. (ed.) Multilingual Brazil: language resources, identitites and ideologies in a globalized world. New York: Routledge, 2018.

; SILVA, I. R. "Já que ele não fala, podia ao menos escrever..." O Grafocentrismo Naturalizado que Insiste em Normalizar o Surdo. In: KLEIMAN, A. B. \& CAVALCANTI, M. C. (orgs.) Linguística Aplicada, Suas Faces e Interfaces. Campinas, SP: Mercado de Letras, p. 219-242, 2007.

DE FINA, A.; BAYNHAM, M. Immigrant discourse. In: CHAPELLE, C. A. The Encyclopedia of Applied Linguistics. Iowa State University: WILEY-BLACKWELL, 2012.

FAVORITO, W. "O difícil são as palavras": representações de/sobre estabelecidos e outsiders na escolarização de jovens e adultos surdos. Campinas, 2006. Tese de doutorado. Instituto de Estudos da Linguagem, UNICAMP.

FENEIS - Federação Nacional de Educação e Integração dos Surdos. A educaçãa que nós surdos queremos. Documento elaborado no pré-congresso ao V Congresso Latino Americano de Educação Bilíngue para Surdos. Porto Alegre/RS:UFRGS, 1999. Disponível em: < https://docslide.com.br/documents/a-educacao-que-nos-surdosqueremos.html >. Acesso em: 03 set. 2017.

Projeto Escola Pública Integral Bilíngue (LIBRAS e Português - Escrito). Brasília, 2011. Disponível em: < http://www.sinprodf.org.br/wpcontent/uploads/2013/06/projeto_escola-bil\%C3\%8Dngue-feneis.pdf >. Acesso em: 04 jun. 2018. 
REVISTA X, Curitiba, volume 13, n.1, p. 230-254, 2018.

Dossiê Especial: Português como Língua Adicional em contextos de minorias:

(co)construindo sentidos a partir das margens

BIZON \& DINIZ (Orgs.)

FERNANDES, S. É possível ser surdo em português? Língua de sinais e escrita: em busca de uma aproximação. In: SKLIAR, C. Atualidade da educação bilíngue para surdos. Porto Alegre, Mediação, 1999. v. 2.

FERNANDES, S.; MOREIRA, L.C. Desdobramentos político-pedagógicos do bilinguismo para surdos: reflexões e encaminhamentos. Revista "Educação Especial, v. 22, n.34, p. 225-236. Santa Maria, 2009. Disponível em: < http://www.ufsm.br/revistaeducacaoespecial >. Acesso em: maio/2013.

GATTI, B. A. Grupo focal na pesquisa em Ciências Sociais e Humanas. Brasília: Liber Livro, 2012.

KRAEMER, F. F. Português Língua Adicional: progressão curricular com base em gêneros do discurso. Porto Alegre, 2012. Dissertação de mestrado. Instituto de Letras, UFRGS. Disponível em: < http://hdl.handle.net/10183/54078 >. Acesso em: 06 mar. 2018.

LANKSHEAR, C.; KNOBEL, M. Pesquisa Pedagógica: do projeto à implementação. Porto Alegre: Artmed, 2008.

LEFFA, V. J. Metodologia do ensino de línguas. In: BOHN, H. I.; VANDRESEN, P. Tópicos em linguística aplicada: $\mathrm{O}$ ensino de línguas estrangeiras. Florianópolis: Ed. da UFSC, 1988, p. 211- 236.

MACHADO, P.C. Integração/Inclusão na Escola Regular: um olhar do egresso surdo. In: QUADROS, R.M. de. (org.) Estudos surdos I: série pesquisas. Petrópolis: Editora Arara Azul LTDA, 2006.

MAHER, T.M. O dizer do sujeito bilíngue: aportes da sociolinguística. In: FAVORITO, W.; GOMES, M.R.; LOUREIRO, V.R.; QUINTIERI, C.S.N.D; RAMOS, M.I.B.B (Orgs.). Anais do seminário desafios e possibilidades na educação bilíngue para surdos. Rio de Janeiro: Editora Líttera Maciel Ltda., 1997.

Do casulo ao movimento: a suspensão das certezas na educação bilíngue e intercultural. Campinas, SP: Mercado de Letras Edições e Livraria Ltda., 2007.

Políticas linguísticas e políticas de identidade: currículo e representações de professores indígenas na Amazônia Ocidental Brasileira. In: Currículo sem fronteiras, v. 10, n. 1, p. 33-48, 2010.

MARCUSCHI, L. A. Gêneros textuais: definição e funcionalidade. In: DIONÍSIO, A. P. et al. Gêneros textuais e ensino. Rio de Janeiro: Lucerna, 2002. 
REVISTA X, Curitiba, volume 13, n.1, p. 230-254, 2018.

Dossiê Especial: Português como Língua Adicional em contextos de minorias:

(co)construindo sentidos a partir das margens

BIZON \& DINIZ (Orgs.)

MATTOS, A. M. de A.; VALÉRIO, K. M. Letramento crítico e ensino comunicativo: lacunas e intersecções. Revista Brasileira de Linguística Aplicada, Belo Horizonte, v. 10, n. 1, p. 135-158, 2010. Disponível em: < http://www.scielo.br/pdf/rbla/v10n1/08.pdf >. Acesso em: 16 fev. 2016.

MOITA LOPES, L. P. Metodologia de pesquisa em Linguística Aplicada: a linguagem como condição e solução. D.E.L.T.A., v. 10, n. 2, p. 328-338, 1994.

Uma linguística aplicada mestiça e ideológica: interrogando o campo como linguista aplicado. In: LOPES, L. P. M. (org.) Por uma linguística aplicada INdisciplinar. São Paulo: Parábola Editorial, 2006. $1^{\mathrm{a}}$ ed. $3^{\mathrm{a}}$ reimpressão.

(Org.). O português no século XXI: cenário geopolítico e sociolinguístico. São Paulo: Parábola Editorial, 2013.

PENNYCOOK, A. Uma linguística aplicada transgressiva. In: LOPES, L. P. M. (org.) Por uma linguística aplicada INdisciplinar. São Paulo: Parábola Editorial, 2006. $1^{\text {a }}$ ed. $3^{\text {a }}$ reimpressão.

PEREIRA, M. C. C. (org.) Leitura, escrita e surdez. $2^{\text {a }}$ Ed. São Paulo: FDE, 2009.

POKER, R. B. Abordagens de ensino na educação da pessoa com surdez. Disponível em: < http://www.marilia.unesp.br/Home/Extensao/LIBRAS/mec_texto2.pdf >. Acesso em: 01 jun. 2013.

QUADROS, R. M; KARNOPP, L. B. Língua de sinais brasileira: estudos linguísticos. Porto Alegre: Artmed, 2004.

RHYMES, B. Communicative repertoire. In: BRIAN, S. \& LEUNG, C. (eds.) Handbook of English Language Studies. Routledge: New York, NY, 2014.

RODRIGUES, V.L. A inclusão é uma confusão: surdos na travessia entre-línguas e práticas escolares. Niterói, 2013. Dissertação de mestrado. Instituto de Letras, UFF.

SALLES, H.M.M.L.S. et al. Ensino de Língua Portuguesa para surdos: caminhos para a prática pedagógica. 1 v. Brasília: MEC, SEESP, 2004.

SANTOS, M. E. P. O cenário multilíngue/multidialetal de fronteira e o processo identitário de alunos brasiguaios no contexto escolar. Campinas, 2004. Tese de doutorado. Instituto de Estudos da Linguagem, UNICAMP.

SCHLATTER, M.; GARCEZ, P. M. Línguas adicionais (Espanhol e Inglês). In: RIO GRANDE DO SUL, Secretaria de Estado da Educação, Departamento Pedagógico. Referenciais curriculares do Estado do Rio Grande do Sul: linguagens, códigos e suas tecnologias. Porto Alegre: SE/DP, 2009, p. 127-172. Disponível em: 
REVISTA X, Curitiba, volume 13, n.1, p. 230-254, 2018.

Dossiê Especial: Português como Língua Adicional em contextos de minorias:

(co)construindo sentidos a partir das margens

BIZON \& DINIZ (Orgs.)

$<$ http://www.educacao.rs.gov.br/\%20pse/\%20html/\%20refer_curric.jsp?ACAO=acao1

>. Acesso em 24 fev. 2012.

SILVA, I.; FAVORITO, W. Surdos na escola: letramento e bilinguismo. Campinas,SP: CEFIEL, 2009.

SKLIAR, C. B. Os estudos surdos em educação: problematizando a normalidade. In: SKLIAR, C.B. (Org.). A surdez:um olhar sobre as diferenças. Porto Alegre: Mediação, 1998. p. 7-31.

WILEY, T. G. Language Planning and policy. In: S. L. MCKAY \& N.H. HORBERGER (orgs.) Sociolinguistics and language teaching. Cambridge: Cambridge University Press, 1996. 